\title{
Initial experience with dual-lumen balloon catheter injection for preoperative Onyx embolization of skull base paragangliomas
}

\author{
Travis R. Ladner, BA, ${ }^{1}$ Lucy He, MD, ${ }^{2}$ Brandon J. Davis, MD, PhD, ${ }^{2}$ George L. Yang, BA, ${ }^{1}$ \\ George B. Wanna, MD, ${ }^{2,3}$ and J Mocco, MD, MS²
}

${ }^{1}$ Vanderbilt University School of Medicine, and Departments of ${ }^{2}$ Neurological Surgery and ${ }^{3}$ Otolaryngology, Vanderbilt University Medical Center, Nashville, Tennessee

\begin{abstract}
OBJECTIVE Paragangliomas are highly vascular head and neck tumors for which preoperative embolization is often considered to facilitate resection. The authors evaluated their initial experience using a dual-lumen balloon to facilitate preoperative embolization in 5 consecutive patients who underwent preoperative transarterial Onyx embolization assisted by the Scepter dual-lumen balloon catheter between 2012 and 2014.
\end{abstract}

METHODS The authors reviewed the demographic and clinical records of 5 patients who underwent Scepter-assisted Onyx embolization of a paraganglioma followed by resection between 2012 and 2014. Descriptive statistics of clinical outcomes were assessed.

RESULTS Five patients ( 4 with a jugular and 1 with a vagal paraganglioma) were identified. Three paragangliomas were embolized in a single session, and each of the other 2 were completed in 3 staged sessions. The mean volume of Onyx used was $14.3 \mathrm{ml}$ (range 6-30 ml). Twenty-seven vessels were selectively catheterized for embolization. All patients required selective embolization via multiple vessels. Two patients required sacrifice of parent vessels (1 petrocavernous internal carotid artery and 1 vertebral artery) after successful balloon test occlusion. One patient underwent embolization with Onyx-18 alone, 2 with Onyx-34 alone, and 1 with Onyx-18 and -34. In each case, migration of Onyx was achieved within the tumor parenchyma. The mean time between embolization and resection was 3.8 days (range 1-8 days). Gross-total resection was achieved in $3(60 \%)$ patients, and the other 2 patients had minimal residual tumor. The mean estimated blood loss during the resections was $556 \mathrm{ml}$ (range 200-850 ml). The mean postoperative hematocrit level change was $-17.3 \%$. Two patients required blood transfusions. One patient, who underwent extensive tumor penetration with Onyx, developed a temporary partial cranial nerve VII palsy that resolved to House-Brackmann Grade I (out of VI) at the 6-month follow-up. One patient experienced improvement in existing facial nerve weakness after embolization.

CONCLUSIONS Scepter catheter-based Onyx embolization seems to be safe and effective. It was associated with excellent distal tumor vasculature penetration and holds promise as an adjunct to conventional transarterial Onyx embolization of paragangliomas. However, the ease of tumor penetration should encourage caution in practitioners who may be able to effect comparable improvement in blood loss with more conservative proximal Onyx penetration.

http://thejns.org/doi/abs/10.3171/2015.5.JNS15124

KEY WORDS paraganglioma; Onyx; liquid embolic material; tumor embolization; catheter; interventional neurosurgery

$\mathrm{P}$ ARAGANGLIOMAS are highly vascular head and neck tumors. As early as 1975 , preoperative embolization before resection has been advocated as a means to improve postoperative outcomes through the minimization of blood loss and better visualization of surgical planes. ${ }^{4,7}$ Given its flow characteristics, Onyx (Covidien) has seen increasing use in the preoperative embolization of tumors, including paragangliomas. , $^{1,5,5,6,17,20,25}$ Direct per- cutaneous puncture is currently the most reported route for Onyx embolization of these tumors, although it is unclear whether that reflects a publication bias or if this modality is actually more common than using transarterial routes of embolization. $3,17,20,25$ Problems with conventional transfemoral artery access, such as tortuosity, atherosclerosis, vasospasm, and small-caliber arterial feeders, may impede complete embolization of these tumors, and danger-

ABBREVIATIONS EBL = estimated blood loss; ECA = external carotid artery; ICA = internal carotid artery; PVA = polyvinyl alcohol.

SUBMITTED January 18, 2015. ACCEPTED May 7, 2015

INCLUDE WHEN CITING Published online October 23, 2015; DOI: 10.3171/2015.5.JNS15124. 
ous anastomoses may increase the risks of intervention. ${ }^{20}$ When transarterial embolization has been attempted, cranial neuropathies are a known complication..$^{5,6}$

Innovations in catheter design may augment transarterial paraganglioma embolization. The Scepter catheter (MicroVention, Inc.), a dual-lumen balloon catheter, was used recently in tumor and arteriovenous malformation embolization procedures. ${ }^{23}$ It has an outer lumen for balloon inflation and an inner working lumen that can accommodate a traditional 0.014-inch microwire. Proximal balloon inflation creates a barrier to Onyx reflux and helps prevent nontarget embolization, whereas the inner lumen enables selective distal target access for embolization. The Scepter obviates the need to form an Onyx plug at the microcatheter tip before attempts to inject it distally, as with traditional Onyx techniques. In this way, the Scepter promotes a quick "plug and push" technique that enables distal penetration. Therefore, this device may obviate some previous concerns with the transarterial embolization of paragangliomas. We review here our initial experience with the preoperative embolization of 5 consecutive paragangliomas using this balloon-assisted technique.

\section{Methods}

We retrospectively analyzed all patients who were undergoing preoperative embolization of a skull base paraganglioma via Scepter-assisted Onyx embolization at Vanderbilt University Medical Center between 2013 and 2014. Data from each patient were collected regarding tumor location and size, preoperative clinical status, the number of embolization procedures per patient, number of feeder tumor vessels, number of vessels catheterized for embolization, volume of Onyx used, percentage of tumor devascularization, volume of contrast, radiation dose, extent of resection, amount of intraoperative blood loss, perioperative transfusion amount, and duration of clinical follow-up. This study was conducted with the approval of our institutional review board.

\section{Operative Procedure}

Under general anesthesia, groin access is gained, and a
6-Fr femoral sheath is placed. A guide catheter is used to catheterize the cervical and cranial vessels of concern. Selective microcatheterization of each feeding artery is done with a Scepter balloon. The Scepter is advanced as distally in the feeding pedicle as possible before balloon inflation for proximal occlusion followed by Onyx embolization. With the balloon in place, minimal reflux occurs, and there is an added ability to "push" the Onyx more distally into the tumor without having to spend a large amount of time developing an Onyx plug. The Scepter balloon is then deflated and, with careful constant pressure, is freed from the Onyx cast that has formed at the tip and is removed. Selective angiography after each pedicle embolization is done to confirm that no unintended embolizations occurred. This process is repeated for all reasonable tumor feeders.

\section{Results}

Between 2013 and 2014, 5 patients with a skull base paraganglioma underwent preoperative embolization with Onyx administered through a Scepter catheter (Table 1). There were 4 jugular paragangliomas and 1 vagal paraganglioma. Three paragangliomas were embolized in a single session; each of the other 2 embolizations were completed in 3 staged sessions over a mean total period of 26 days.

Twenty-seven vessels were selectively catheterized for embolization (Table 2). All patients required selective embolization via multiple vessels. Two patients required sacrifice of parent vessels after successful balloon test occlusion (1 petrocavernous internal carotid artery [ICA] and 1 vertebral artery). The mean volume of Onyx used was $14.3 \mathrm{ml}$ (range 6-30 ml). One patient underwent embolization with Onyx-18 alone, 2 with Onyx-34 alone, and 1 with Onyx-18 and -34. In each case, migration of Onyx was achieved within the tumor parenchyma.

The mean devascularization rate was 64\%; a particularly aggressive tumor (in Case 1) had no reduction in angiographic blush despite 3 rounds of embolization and ICA sacrifice (after passing balloon test occlusion). The mean contrast dose per procedure was $105 \mathrm{ml}$ (range 46-127

TABLE 1. Baseline characteristics of 5 patients with glomus tumor who underwent Onyx embolization assisted by a Scepter catheter

\begin{tabular}{|c|c|c|c|c|c|}
\hline $\begin{array}{l}\text { Case } \\
\text { No. }\end{array}$ & $\begin{array}{c}\text { Paraganglioma } \\
\text { Type }\end{array}$ & Location & Size $(\mathrm{cm})$ & Preoperative Deficit(s) & Supplying Vessels \\
\hline 1 & Jugular & Lt jugular foramen & $3.1 \times 2.6 \times 5.3$ & $\begin{array}{l}\text { CN VII, VIII, XII } \\
\text { (recurrent), previous } \\
\text { resection }\end{array}$ & $\begin{array}{l}\text { ECA: occipital artery, IMA, ascending pharyngeal branch- } \\
\text { es, inferior ECA branches; ICA: multiple small vessels } \\
\text { from petrous \& cavernous ICA, rt meningohypophyseal } \\
\text { trunk; vertebrobasilar: extracranial VA vessels, It AICA }\end{array}$ \\
\hline 2 & Jugular & $\begin{array}{l}\text { Lt jugular foramen, } \\
\text { pharyngeal } \\
\text { space }\end{array}$ & $\begin{array}{l}4.3 \times 4.8 \times 3.7 \\
\quad \text { (intracranial) } \\
4 \times 3.5 \times 4.5 \\
\quad(\text { extracranial })\end{array}$ & $\begin{array}{l}\text { CN VII, VIII, } X \text { (recur- } \\
\text { rent), previous } \\
\text { resection }\end{array}$ & $\begin{array}{l}\text { ECA: } 5 \text { separate feeding vessels; ICA: feeder from petro- } \\
\text { sal ICA, meningohypophyseal trunk; vertebrobasilar: } \\
\text { multiple VA feeders; other: thyrocervical trunk }\end{array}$ \\
\hline 3 & Jugular & Rt jugular foramen & $4.7 \times 2.5 \times 3.5$ & CNX & ECA: 2 retroauricular branches, IMA, occipital artery \\
\hline 4 & Jugular & Rt middle ear & $2.1 \times 1.4 \times 1.9$ & None & ECA: 3 separate feeding vessels \\
\hline 5 & Vagal & $\begin{array}{l}\text { Rt middle ear, } \\
\text { middle fossa }\end{array}$ & $4.3 \times 2.6 \times 3.7$ & None & ECA: rt occipital, 3 separate feeding vessels \\
\hline
\end{tabular}

$\mathrm{AICA}=$ anterior inferior cerebellar artery; $\mathrm{CN}=$ cranial nerve; IMA = internal maxillary artery; VA = vertebral artery. 
$\mathrm{ml}$ ), and the mean dose per patient was $189.4 \mathrm{ml}$ (range $76-412 \mathrm{ml}$ ) (Table 2). The mean radiation dose per procedure was $3.6 \mathrm{~Gy}$ (range 2-6.3 Gy), and the mean dose per patient was 7.1 Gy (range 2-15.1 Gy). The mean fluoroscopy time per procedure was 40 minutes (range 20.8-66.1 minutes), and the mean time per patient was 72 minutes (range 20.8-158.3 minutes).

The mean time between final embolization and resection was 3.8 days (range 1-8 days) (Table 3 ). Grosstotal resection was achieved in $3(60 \%)$ patients, and the other 2 patients had minimal residual tumor. The mean estimated blood loss (EBL) during resection was $556 \mathrm{ml}$ (range 200-850 ml). The mean postoperative hematocrit level was $28.4 \%$ (range $22 \%-32 \%$ ), and the mean change was $-17.3 \%$. Two patients received blood transfusions. The temporary cranial nerve palsy rate was $20 \%$, and the permanent cranial nerve palsy rate was $0 \%$. One patient (Case 4) developed a new partial cranial nerve VII palsy after embolization that had resolved completely by clinical follow-up. Conversely, 1 patient (Case 1) experienced improvement in existing facial nerve weakness after the embolization.

\section{Illustrative Case \\ Case 5}

One patient with a history of hearing loss was found on routine evaluation to have a vascular lesion in the right middle ear. MRI revealed an extensive glomus jugulare with involvement of the middle ear and middle cranial fossa. Angiography revealed that the tumor was supplied by 4 branches of the external carotid artery (ECA) that were embolized in the described technique using the Scepter and Onyx (Fig. 1). The focus of embolization was to shut down the proximal feeding pedicles to the point of superficial tumor penetration but to avoid deep tumor penetration with the Onyx. Coil embolization of the right occipital artery distal to multiple small feeding branches was done to prevent unnecessary distal occipital embolization and to minimize the possibility of any Onyx reflux into the vertebral artery via the occipitovertebral collaterals. Onyx embolization with the Scepter was then undertaken by using a standard technique. Tumor devascularization was $95 \%$. There were no postembolization complications. Resection proceeded 5 days later with a mastoidectomy and transcochlear, transjugular, transsigmoid resection of the tumor. There were no surgical complications, the EBL was $350 \mathrm{ml}$, there were no intraoperative blood transfusions, and the hematocrit level changed from $36 \%$ to $31 \%$ postoperatively.

\section{Discussion}

Paragangliomas are rare extraadrenal neuroendocrine tumors that account for $0.6 \%$ of all head and neck tumors. ${ }^{19}$ These tumors are highly vascular, with upregulation of several angiogenesis factors. ${ }^{9} 11,21$ Historically, early attempts at resection have been impeded by challenging anatomical tumor location, complex tumor anatomy, and robust tumor vascularity that causes excessive blood loss during resection. ${ }^{4,15}$

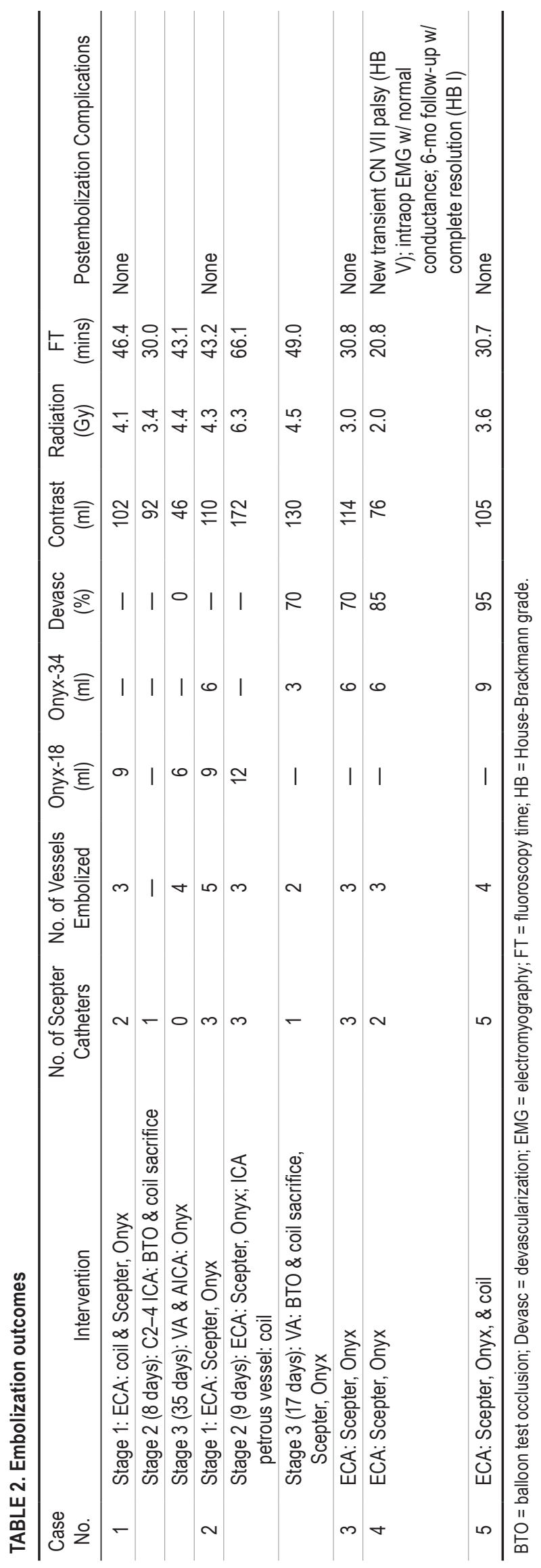

J Neurosurg Volume $124 \cdot$ June 2016 
TABLE 3. Resection outcomes

\begin{tabular}{|c|c|c|c|c|c|c|c|}
\hline \multirow{2}{*}{$\begin{array}{l}\text { Case } \\
\text { No. }\end{array}$} & \multirow{2}{*}{$\begin{array}{c}\text { Days From 1st Embolization } \\
\text { to Resection }\end{array}$} & \multirow{2}{*}{$\begin{array}{c}\text { Days From Last } \\
\text { Embolization to Resection }\end{array}$} & \multirow[b]{2}{*}{ GTR } & \multirow{2}{*}{$\begin{array}{l}\mathrm{EBL} \\
(\mathrm{ml})\end{array}$} & \multirow{2}{*}{$\begin{array}{l}\text { No. of } \\
\text { Transfusions }\end{array}$} & \multicolumn{2}{|c|}{$\mathrm{HCT}(\%)$} \\
\hline & & & & & & Before Embolization & After Embolization \\
\hline 1 & 51 & 8 & No & 700 & 4 (pRBC) & 31 & 32 \\
\hline 2 & 30 & 4 & No & 850 & $2(p R B C)$ & 35 & 26 \\
\hline 3 & 1 & 1 & Yes & 200 & - & 35 & 31 \\
\hline 4 & 1 & 1 & Yes & 680 & - & 36 & 22 \\
\hline 5 & 5 & 5 & Yes & 350 & - & 36 & 31 \\
\hline
\end{tabular}

GTR = gross-total resection; $\mathrm{HCT}=$ hematocrit; $\mathrm{pRBC}=$ packed red blood cells .

Preoperative embolization was introduced in the 1970s. ${ }^{7}$ The goal was to minimize blood flow to the tumor and thereby decrease blood loss and enable better visualization of surgical planes, which increases the likelihood of gross-total resection and minimizes nerve injury. Early on, large catheters combined with bulkier embolic agents hindered efforts to selectively catheterize tumor feeders beyond the tertiary ECA branches. ${ }^{4}$ Since modern techniques have been adopted, these tumors have been embolized with materials including polyvinyl alcohol (PVA), Gelfoam, $N$-butyl cyanoacrylate, microcoils, and Onyx. ${ }^{1}$

Murphy and Brackmann ${ }^{16}$ described a reduction in intraoperative blood loss from 2769 to $1122 \mathrm{ml}$ using PVA
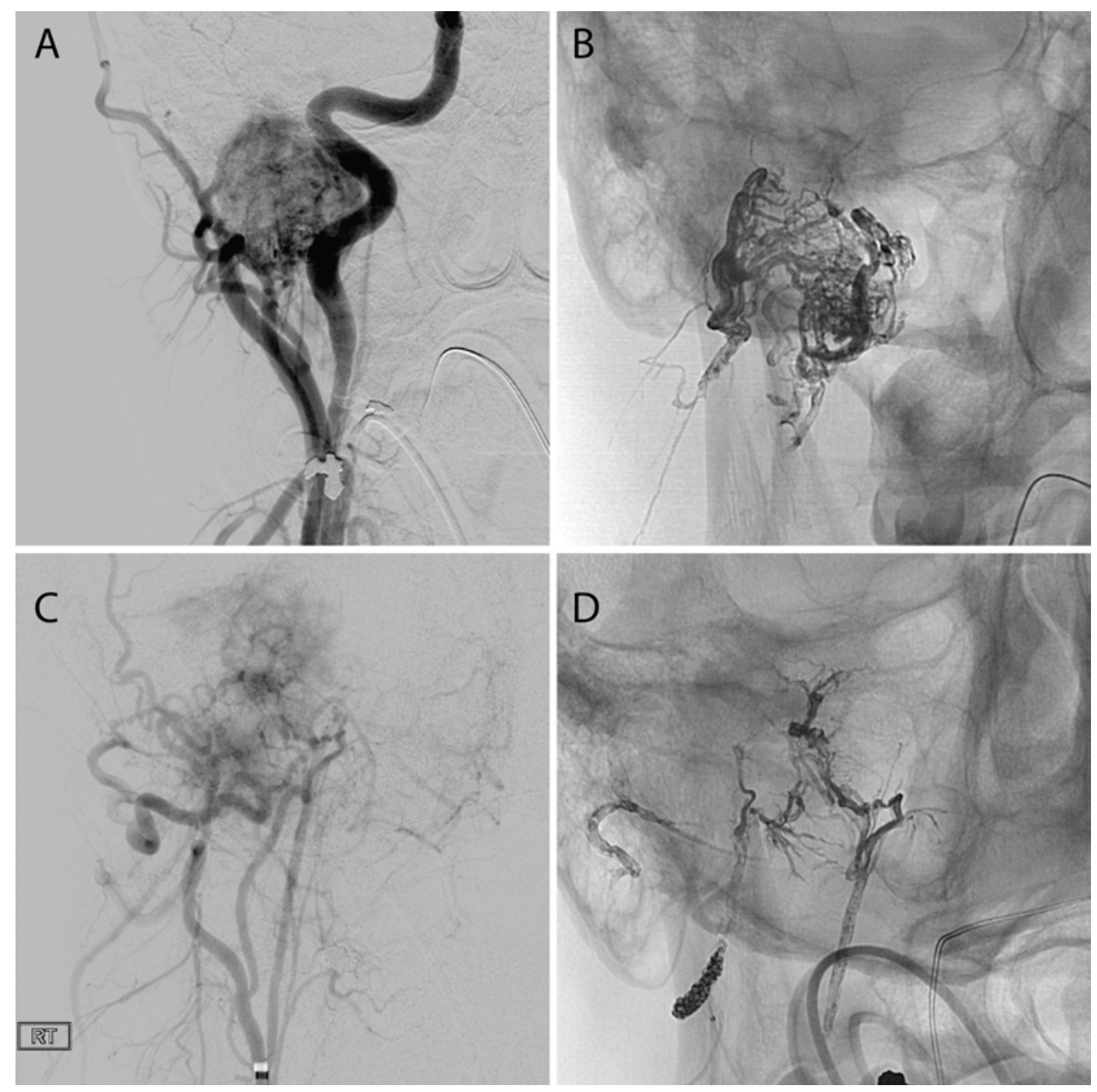

FIG. 1. A: Case 4 (aggressive embolization with temporary cranial nerve palsy). Preembolization subtracted angiogram showing a $2.1 \times 1.4 \times 1.9-\mathrm{cm}$ right middle ear jugular paraganglioma on common carotid artery injection. B: Postembolization unsubtracted angiogram showing dense Onyx penetration within the tumor parenchyma. C: Case 5 (conservative proximal pedicle embolization). Preembolization subtracted angiogram showing a $4.3 \times 2.6 \times 3.7-\mathrm{cm}$ right middle ear and middle cranial fossa vagal paraganglioma on ECA injection. D: Postembolization unsubtracted angiogram showing Onyx penetration; note that the Onyx cast is in the feeding pedicles and periphery. The coil mass can be seen in the occipital artery. 
embolization in skull base glomus jugulare tumors. In a later series in which PVA, Gelfoam, and $N$-butyl cyanoacrylate were used, the mean EBLs for glomus jugulare and glomus vagale tumors with skull base extension were between 450 and $494 \mathrm{ml}^{18}$ The mean EBL in our series $(556 \mathrm{ml})$ is comparable, although we are unable to make a statistical assessment. We found no satisfactory reports on bleeding after transarterial Onyx embolization of skull base paragangliomas, and we were also unable to identify appropriate nonembolization controls at our institution. Bleeding in our series was comparable to that in previous reports of preoperative embolization with non-Onyx agents and was perhaps less so when compared with historical nonembolized cases in the literature.

Only recently was Onyx embolization reported for use in these tumors. ${ }^{1,3,5,6,17,20,25}$ Its cohesive properties enable the core of the embolic material to propel forward into the tumor vasculature. Compared with earlier embolic materials, Onyx precipitates gradually and has a lower viscosity, which may enable longer, more controlled injections into the tumor nidus. ${ }^{17,20}$ Two injection routes are possible: transarterial, with selective catheterization of tumor feeders, and direct percutaneous tumor injection.

There are 4 previous reports of percutaneous injection with Onyx and 3 previous reports of transarterial embolization. Wanke et al. ${ }^{25}$ first reported a series of 6 patients who underwent direct puncture for carotid body tumors in 2009. They elected the percutaneous route secondary to concern that access to tiny tumor-feeding vessels would not be feasible transarterially. They reported total devascularization in all their cases. In 2010, Ozyer et al. ${ }^{17}$ reported a single jugular paraganglioma treated with percutaneous Onyx embolization, which achieved partial embolization and subsequently resulted in subtotal resection, with the patient requiring transfusion. In a series of 7 carotid body tumors, Shah et al. ${ }^{20}$ achieved complete devascularization with percutaneous Onyx embolization in 2012. Around the same time, Elhammady et al. ${ }^{3}$ reported 9 carotid body tumors and 3 jugular paragangliomas; the mean devascularization rate was $88 \%$ after percutaneous Onyx embolization, and the mean EBL during resection was $506 \mathrm{ml}$. These methods seem to be effective for tumors located in the neck, but there have been few reports on those with skull base extension.

In 2012, Alaraj et al. ${ }^{1}$ reported the first case of transarterial Onyx embolization for a vagal paraganglioma. They achieved adequate tumor devascularization but encountered retrograde migration of Onyx into the vertebral artery, which required coil-mediated vessel sacrifice. Gartrell et al..$^{5}$ reported the first 3 cases of postembolization cranial neuropathies after transarterial Onyx embolization of paragangliomas. In each case, near-complete tumor devascularization was achieved. In 2014, in the largest series of transarterial Onyx embolization for paraganglioma to date, despite a mean tumor devascularization rate of $90.7 \%$, Gaynor et al. ${ }^{6}$ reported that $2(18 \%)$ of 11 patients developed new, permanent cranial neuropathies after embolization. These authors attributed those cranial neuropathies to the intimate relationship between tumor vessels and the vasa nervorum of cranial nerves. This report has led others to recommend that physicians "halt the use of
Onyx for preoperative tumor embolization" in favor of other materials such as PVA. ${ }^{14}$

Major limitations with transarterial Onyx embolization have been 1) challenges with access to small arterial feeders and 2) nontarget Onyx embolization. Anecdotally, the described Scepter technique might provide the operator with greater technical control of the procedure and Onyx migration. The Scepter's safety and efficacy in Onyx embolization for arteriovenous malformations and dural arteriovenous fistulas have been described. , $10,12,22,23$ Recently, we showed that the use of the Scepter catheter during preoperative Onyx embolization of spinal tumors is safe and effective, with an associated decrease in intraoperative bleeding and transfusion requirements compared with those in procedures performed with traditional catheters. ${ }^{13}$ However, given a lack of controls, we are unable to make such an assessment in our series of patients with paraganglioma.

The Scepter's inner lumen allows the incorporation of a traditional 0.014-inch microwire, which makes the catheter navigable to distal targets, perhaps even in the setting of tortuosity. ${ }^{23}$ This navigability might facilitate easier access and embolization of tumors for the neurointerventionist. The inflated balloon creates a temporary plug, which prevents the lengthy process of creating a proximal Onyx plug, as is done with traditional microcatheters, to minimize reflux. ${ }^{2}$ This technique may decrease nontarget embolization ${ }^{23}$ and facilitate smoother microcatheter extraction as well, which has been hypothesized to contribute to cranial neuropathy in the case of excess traction. ${ }^{2}$

When there are manifold vascular feeders to embolize, as in paragangliomas, the Scepter catheter might result in decreased operative time and radiation exposure. From previous experiences with transarterial Onyx embolization of these tumors, Gaynor et al. ${ }^{6}$ reported a mean fluoroscopy time of 83 minutes, which might be longer than that in our series ( 40 minutes per procedure or 72 minutes per patient); however, we are unable to determine if this difference is statistically significant. Radiation exposure during neurointervention is a concern, particularly for patients who receive multiple staged procedures. Our mean exposure per procedure was $3.9 \mathrm{~Gy}$, which increases concern for skin radiation injuries; ${ }^{24}$ however, no patient in this series experienced such a dermatological problem.

Despite these potential positive aspects, there are important lessons to be learned in the use of this technique. Although our patients experienced no permanent neurological injury, 1 patient did experience a significant temporary cranial nerve VII palsy that resolved to HouseBrackmann Grade I at the 6-month follow-up (Case 4). ${ }^{8}$ Based on intraoperative evaluation during resection, we believe that it was secondary to overly aggressive and excessive tumor penetration with the Onyx. By preventing reflux, the Scepter catheter might enhance the anterograde propulsion of Onyx into the tumor's vascular bed; however, there may be a risk of excessive embolization.

The ease of penetration with the Scepter can lure the surgeon into pursuing a degree of embolization that provides limited further benefit but may carry increased risk; this was our experience with Case 4, in whom the tumor was densely embolized (Fig. 1). The temporary facial 
nerve palsy that developed is a cautionary tale in our early experience with this technique. It is very much worth noting that this procedure resulted in the shortest fluoroscopy time in the series (20.8 minutes), despite embolizing through 3 feeders with a total of $6 \mathrm{ml}$ of Onyx being injected, which highlights the potential for rapid aggressive embolization. The tumor in this case completely encased the facial nerve, and in our efforts to penetrate the tumor completely, we suspect that inadvertent embolization of the vasa nervorum occurred, despite no angiographic evidence of Onyx migration or nontarget embolization. The Onyx cast also may have had a compressive effect on the nerve itself. At the 1-month follow-up, the patient's facial nerve palsy had improved, and outpatient electromyography (EMG) revealed normal nerve conductance. By the 6-month follow-up, the facial nerve palsy had resolved completely. Based on this experience, we have made a more deliberate effort to ensure that proximal, but not distal/deep, tumor embolization is effected (as in Case 5 [Fig. 1]), thereby minimizing the risk to adjacent cranial nerves. Although we acknowledge this complication as a hypothetical concern without histopathological evidence, the only patient in the series to develop a new deficit had the densest Onyx cast, and results from a previous transarterial series of paragangliomas embolized with Onyx mirror ours, with a reported $18 \%$ permanent cranial nerve palsy rate. ${ }^{6}$ However, in other series in which non-Onyx embolization was used, the facial nerve palsy rate can be as high as $36.8 \%$ (7 of 19$){ }^{18}$

In addition, we acknowledge the limitations of this small retrospective study, in which we examined our experience with a new device in the hands of a single operator. Another limitation is that ours was not a controlled study; we were unable to find suitable controls from our institution. The best that can be offered are historical controls from the literature related to paraganglioma treatment. Given that there are no clear guidelines about preoperative embolization for these tumors, it is unlikely that a true randomized controlled trial will be conducted in the future to ascertain whether embolization is superior to open resection alone. However, the results from our series, along with those available in the literature, support the idea that embolization may help to reduce intraoperative blood loss and achieve more robust resection. Furthermore, use of the Scepter-and-Onyx technique enables the surgeon to achieve adequate tumor penetration without the need for transcutaneous access and seems to have a safe risk profile in terms of permanent cranial nerve injury, radiation exposure, and/or unintended embolization events.

\section{Conclusions}

We have presented some data to suggest that the Scepter catheter results in a low incidence of reflux while enabling distal tumor feeder penetration, and it may be a useful adjunct to conventional transarterial Onyx embolization of paragangliomas. Our single occurrence of partial temporary cranial neuropathy in this series seemed to be secondary to excessive deep embolization of the tumor, which, upon surgery, fully encased the facial nerve. This technique enables excellent tumor embolization; however, surgeons should consider avoiding excessive distal tumor penetration to minimize the risk of such complications.

\section{References}

1. Alaraj A, Pytynia K, Carlson AP, Krishna PH, Charbel FT, Amin-Hanjani S, et al: Combined preoperative onyx embolization and protective internal carotid artery covered stent placement for treatment of glomus vagale tumor: review of literature and illustrative case. Neurol Res 34:523-529, 2012

2. Dabus G, Linfante I, Martínez-Galdámez M: Endovascular treatment of dural arteriovenous fistulas using dual lumen balloon microcatheter: technical aspects and results. Clin Neurol Neurosurg 117:22-27, 2014

3. Elhammady MS, Peterson EC, Johnson JN, Aziz-Sultan MA: Preoperative onyx embolization of vascular head and neck tumors by direct puncture. World Neurosurg 77:725-730, 2012

4. Forbes JA, Brock AA, Ghiassi M, Thompson RC, Haynes DS, Tsai BS: Jugulotympanic paragangliomas: 75 years of evolution in understanding. Neurosurg Focus 33(2):E13, 2012

5. Gartrell BC, Hansen MR, Gantz BJ, Gluth MB, Mowry SE, Aagaard-Kienitz BL, et al: Facial and lower cranial neuropathies after preoperative embolization of jugular foramen lesions with ethylene vinyl alcohol. Otol Neurotol 33:12701275,2012

6. Gaynor BG, Elhammady MS, Jethanamest D, Angeli SI, Aziz-Sultan MA: Incidence of cranial nerve palsy after preoperative embolization of glomus jugulare tumors using Onyx. J Neurosurg 120:377-381, 2014

7. Hilal SK, Michelsen JW: Therapeutic percutaneous embolization for extra-axial vascular lesions of the head, neck, and spine. J Neurosurg 43:275-287, 1975

8. House JW, Brackmann DE: Facial nerve grading system. Otolaryngol Head Neck Surg 93:146-147, 1985

9. Hussain I, Husain Q, Baredes S, Eloy JA, Jyung RW, Liu JK: Molecular genetics of paragangliomas of the skull base and head and neck region: implications for medical and surgical management. J Neurosurg 120:321-330, 2014

10. Jagadeesan BD, Grigoryan M, Hassan AE, Grande AW, Tummala RP: Endovascular balloon-assisted embolization of intracranial and cervical arteriovenous malformations using dual-lumen coaxial balloon microcatheters and Onyx: initial experience. Neurosurgery 73 (2 Suppl Operative):ons238ons243, 2013

11. Jyung RW, LeClair EE, Bernat RA, Kang TS, Ung F, McKenna MJ, et al: Expression of angiogenic growth factors in paragangliomas. Laryngoscope 110:161-167, 2000

12. Kim ST, Jeong HW, Seo J: Onyx embolization of dural arteriovenous fistula, using Scepter C balloon catheter: a case report. Neurointervention 8:110-114, 2013

13. Ladner TR, He L, Lakomkin N, Davis BJ, Cheng JS, Devin CJ, et al: Minimizing bleeding complications in spinal tumor surgery with preoperative Onyx embolization via dual-lumen balloon catheter. J Neurointerv Surg [epub ahead of print], 2014

14. Lanzino G, Burrows AM, Cloft HJ: Onyx embolization. J Neurosurg 120:375-376, 2014

15. Michael LM II, Robertson JH: Glomus jugulare tumors: historical overview of the management of this disease. Neurosurg Focus 17(2):E1, 2004

16. Murphy TP, Brackmann DE: Effects of preoperative embolization on glomus jugulare tumors. Laryngoscope 99:12441247,1989

17. Ozyer U, Harman A, Yildirim E, Aytekin C, Akay TH, Boyvat $F$ : Devascularization of head and neck paragangliomas by direct percutaneous embolization. Cardiovasc Intervent Radiol 33:967-975, 2010 
18. Persky MS, Setton A, Niimi Y, Hartman J, Frank D, Berenstein A: Combined endovascular and surgical treatment of head and neck paragangliomas--a team approach. Head Neck 24:423-431, 2002

19. Robertson JH, Gardner G, Cocke EW Jr: Glomus jugulare tumors. Clin Neurosurg 41:39-61, 1994

20. Shah HM, Gemmete JJ, Chaudhary N, Pandey AS, Ansari SA: Preliminary experience with the percutaneous embolization of paragangliomas at the carotid bifurcation using only ethylene vinyl alcohol copolymer (EVOH) Onyx. J Neurointerv Surg 4:125-129, 2012

21. Span PN, Rao JU, Oude Ophuis SBJ, Lenders JWM, Sweep FCGJ, Wesseling P, et al: Overexpression of the natural antisense hypoxia-inducible factor-1alpha transcript is associated with malignant pheochromocytoma/paraganglioma. Endocr Relat Cancer 18:323-331, 2011

22. Spiotta AM, James RF, Lowe SR, Vargas J, Turk AS, Chaudry MI, et al: Balloon-augmented Onyx embolization of cerebral arteriovenous malformations using a dual-lumen balloon: a multicenter experience. J Neurointerv Surg [epub ahead of print], 2014

23. Spiotta AM, Miranpuri AS, Vargas J, Magarick J, Turner RD, Turk AS, et al: Balloon augmented Onyx embolization utilizing a dual lumen balloon catheter: utility in the treatment of a variety of head and neck lesions. J Neurointerv Surg 6:547-555, 2014

24. Vano E, Fernandez JM, Sanchez RM, Martinez D, Ibor LL, Gil A, et al: Patient radiation dose management in the followup of potential skin injuries in neuroradiology. AJNR Am J Neuroradiol 34:277-282, 2013

25. Wanke I, Jäckel MC, Goericke S, Panagiotopoulos V, Dietrich U, Forsting M: Percutaneous embolization of carotid paragangliomas using solely Onyx. AJNR Am J Neuroradiol 30:1594-1597, 2009

\section{Disclosure}

Dr. Mocco is a consultant for Lazarus Effect, Medina Medical, Pulsar Vascular, Reverse Medical, and Edge Therapeutics; an investor in Blockade Medical and Medina Medical; and on the advisory board for Codman Neurovascular.

\section{Author Contributions}

Conception and design: Ladner, He, Davis, Mocco. Acquisition of data: Ladner, He, Yang. Analysis and interpretation of data: Ladner, He, Davis, Wanna, Mocco. Drafting the article: Ladner, He. Critically revising the article: He, Davis, Yang, Mocco. Reviewed submitted version of manuscript: all authors. Approved the final version of the manuscript on behalf of all authors: Ladner. Statistical analysis: Ladner. Study supervision: Mocco.

\section{Supplemental Information}

Previous Presentation

Portions of this work were presented as a digital poster at the 2015 American Association of Neurological Surgeons/Congress of Neurological Surgeons Cerebrovascular Section held in Nashville, TN, on February 9, 2015.

\section{Correspondence}

Travis R. Ladner, Vanderbilt University School of Medicine, 201 Light Hall, 2215 Garland Ave., Nashville, TN 37232. email: travis.r.ladner@vanderbilt.edu. 